\title{
El libro de Fenggang Yang, Religion in China. Survival \& Revival under Communist Rule
}

\author{
Ricardo Martínez Esquivel \\ Sede del Pacífico \\ Universidad de Costa Rica
}

\begin{abstract}
Resumen
El autor realiza una lectura crítica del libro Religion in China. Survival \& Revival under Communist Rule del especialista de origen chino Fenggang Yang (publicado en 2012), durante el gobierno de Mao Zedong y el Partido Comunista Chino y su marcado interés en la secularización del pueblo por medio del ateísmo.
\end{abstract}

Palabras claves: religión, China, transformación espiritual

\begin{abstract}
The author makes a critical reading of the book Religion in China. Survival \& Revival under Communist Rule by the Chinese specialist Fenggang Yang (published in 2012) during the government of Mao Zedong and the Chinese Communist Party and their process of secularization by means of atheism.
\end{abstract}

Key words: religion, China, spiritual transformation

$\mathrm{E}$ n la década de 1920, todavía con el calor del movimiento del 4 de mayo (1919), el filósofo Hu Shih 胡適 (1891-1962) señaló: "China es un país sin religión y los chinos no son un pueblo regido por las supersticiones religiosas" ${ }^{\prime}$. No obstante, casi un siglo de investigaciones sobre la religiosidad en China, han demostrado su constante participación en la historia. Acerca de ello, el sociólogo C. K. Yang ha indicado: "No hay un rincón en la gran tierra de China [antes de 1949], donde no se encuentren templos, santuarios, altares y otros lugares de culto, que sean una indicación visible de la fuerte y generalizada influencia de la religión 
en la sociedad china"2. Pero, ¿qué ha sucedido desde la llegada al poder del Partido Comunista Chino (PCCh)?

Desde 1949, el PCCh ha llevado a cabo campañas de erradicación de movimientos religiosos (1949-1953), procesos de secularización por medio de la promoción del ateísmo en el sistema educativo o el intento de transformar las llamadas "grandes religiones" (daoísmo, budismo, Islam, catolicismo y protestantismo) en sociedades patrióticas o civiles, y las brutales persecuciones durante la Revolución Cultural (19661976) con el consecuente desarrollo del culto a la personalidad de Mao Zedong. Sin embargo, la religión en China ha sobrevivido. Prueba de su importancia como actor social se observa en la institucionalización de la libertad de culto en las diferentes constituciones políticas $(1954,1975 \text { y 1982) })^{3}$, la promulgación del documento \#19 de 1982 para la regulación de las religiones, la organización de la unidad estatal de asuntos religiosos en 1998 o las resoluciones legislativas para la prohibición de los xie jiao邪教 o cultos heréticos en 1999 a raíz de los sucesos del Falun Gong法 輪功durante la década de 1990.¿Cómo pudo la religión sobrevivir y revivir bajo el régimen comunista chino?

Esta problemática motivó a Fenggang Yang en Religion in China a plantear las siguientes preguntas: ¿Cuánto puede el control estatal hacer crecer o decrecer las religiones? ¿Hasta dónde un estado secular promueve la secularización? Si una fuerte regulación no es efectiva en la reducción de la participación religiosa, ¿cuáles son las causas y las consecuencias? ¿Qué teoría podría ayudar en la comprensión de la resistencia de la religión en una sociedad con un quinto de la población mundial?
Para responder a ellas, Yang, profesor de sociología, director de Center on Religion and Chinese Society (desde 2008) y de Review of Religion and Chinese Society (desde 2014), en Perdue University, propone un enfoque político-económico para analizar la supervivencia y el renacimiento de la religión en China. Explica que a pesar de las regulaciones restrictivas impulsadas desde el ateísmo, la religión se ha reactivado en todo el país. Yang argumenta que la economía religiosa china bajo el régimen comunista es una economía de escasez, donde se regula en gran medida la oferta, mientras que la demanda adquiere una dinámica vivaz y las regulaciones religiosas se vuelven ineficaces debido a la "mano invisible" de las fuerzas del mercado. En este sentido, según el autor, se desarrolla un triple mercado religioso: rojo (religiones legales), negro (ilegales) y gris (estatus legal ambiguo, por lo general son religiones legales realizando actividades ilegales o disfrazadas como culturales o científicas).

En el capítulo 1, Yang realiza un estado de la cuestión de la sociología de la religión, con el objetivo de discutir el cambio del paradigma de la secularización al nuevo paradigma de la vitalidad religiosa, y propone una aproximación político-económica para explicar la religión durante el gobierno del PCCh. El paradigma de la secularización, siguiendo a Max Weber (18641920), predice el inevitable declive de las creencias religiosas o de los significados sociales de la religión a medida que se construye la modernidad, situación que no sucede en China. Por ende, partiendo de la idea de Rodney Stark y Roger Finke ${ }^{4}$ sobre paradigmas teóricos universales y basado en la teoría del triple mercado religioso, así como 
del concepto económico de "escasez" de János Kornai ${ }^{5}$, Yang plantea que el ateísmo llevó al PCCh a restringir la oferta de lo religioso y suprimir la demanda religiosa o erradicarla cuando lo vieron posible. Empero, el autor está consciente del cuidado que se debe tener de no equiparar la economía religiosa con la economía material, ya que la primera no trata sólo de productos y servicios, sino de un complejo fenómeno social, psicológico y espiritual. Ahora bien, ¿qué debe y qué no ser considerado como religión o religioso?

Ésta es la pregunta que introduce el capítulo 2, en el cual Yang plantea su definición de religión. Retomando las propuestas conceptuales del sociólogo Émile Durkheim (1858-1917) ${ }^{6}$ y los antropólogos E. B. Tylor $(1832-1917)^{7}$ y Clifford Geertz (1926-2006) ${ }^{8}$, así como teniendo en cuenta las consecuencias de la modernidad en las religiones (diferenciación institucional y pluralidad religiosa -pág. 34-), Yang define la religión como "un sistema unificado de creencias y prácticas sobre la vida y el mundo relativo a lo supernatural, cuyos creyentes o seguidores se organizan socialmente en una comunidad moral" (traducción propia, pág. 36). De esta definición se pueden identificar cuatro elementos: la creencia en lo supernatural, un grupo de creencias sobre la vida y el mundo, un grupo de prácticas rituales que manifiestan las creencias y una organización social distintiva de los creyentes y practicantes. También, Yang propone cuatro categorías que tienen al menos tres de los elementos anteriores: la religión total (cristianismo, budismo e Islam), las semirreligiones (religiones populares, magia y espiritualidades), las cuasirreligiones (religiones civiles, culto a los ancestros y cultos gremiales) y las pseudorreligiones (ateísmo, comunismo y fetichismos) $)^{9}$.

No obstante, en la definición de Yang identificamos una serie de problemas. Primero, no tiene en cuenta que en China la religión ha sido una actividad tan intrínseca en otras esferas sociales, difícil de diferenciar e integrada por completo a la vida cotidiana desde tiempos muy remotos ${ }^{10}$. Asimismo, en el mundo chino históricamente ha sido normal la convivencia de prácticas confucianas, budistas, daoístas y hasta cristianas ${ }^{11}$. Por lo tanto, hizo falta un análisis etimológico del término chino que se traduce por religión: zongjiao宗教. Por otra parte, la definición planteada por Yang tiene como base la modernidad, claramente interpretada como una serie de procesos intraeuropeos (esto también conlleva problemas de historicidad en los conceptos empleados). ¿Cómo se construye la modernidad en la historia de China? ¿Cuál es la modernidad china para el periodo de gobierno del PCCh? ¿Esta modernidad cómo determina la concepción de lo religioso en China? Son cuestionamientos que el autor no toma en cuenta. Otro problema es la fuerte inclinación al teísmo y la trascendencia, el sistema y la organización, algo similar a lo hecho por el PCCh, que relega las religiones populares a la categoría de la superstición y el atraso. Por último, estas categorías dicen poco de la naturaleza de la religión, la religiosidad o el impulso religioso (Marcel Gauchet ${ }^{12}$ ), ya que se plantea una analogía con la economía de mercado, reduciéndose lo religioso a una mercancía. Esto, a pesar de que se señaló la intención de equiparar la economía religiosa con una economía materialista (pág. 21). 
En el capítulo 3, se examinan los cambios, los debates y las diversas maneras en que se comprende, aplica e interpreta el ateísmo marxista chino, así como sus implicaciones en la política religiosa. Este examen no se reduce a la dinámica política. Como se explica en el capítulo 1 , la rehabilitación del concepto de la cultura en el análisis científico como un concepto con su propio significado ha matizado la religión como parte de un fenómeno cultural. Yang habla de tres dimensiones del ateísmo en China: el militante (puro y duro), el ilustrado (más abierto) y el leve. El ateísmo se va a expresar dependiendo del contexto. Si el orden social es estable, la política religiosa del PCCh es más laxa; bajo la amenaza interna o externa, el ateísmo sería militante, como ocurrió durante la primera campaña de erradicación de movimientos religiosos o la Revolución Cultural.

Por su parte, en el capítulo 4 se describe la evolución histórica de las políticas religiosas del PCCh a partir de la propuesta de cuatro periodos: 1949-1957: control político de los grupos religiosos (supresión de los huidaomen會道門y transformación de las "cinco grandes" religiones en sociedades patrióticas-civiles); 1957-1966: la transformación socialista se impuso a los grupos religiosos patrióticos y con fuerza redujo el número de sus espacios de reunión; 1966-1979: se cerraron espacios de reunión, ocurrió la Revolución Cultural, la religión desapareció de la escena pública, adquirió un carácter secreto y clandestino, y se desarrolló el culto a la personalidad de Mao; y 1979-2009: mayor institucionalización de una normativa de control gubernamental de las actividades religiosas (en este periodo surgen los qigong气功).
Uno de los objetivos principales en Religion in China consiste en ofrecer una base teórica para comprender e interpretar la religión en China. De esto tratan los capítulos finales (5, 6 y 7). Yang a partir de la teoría de los mercados -como se conoce en la sociología de la religión-, se centra en las nociones de la demanda, la oferta y la regulación que, según los autores de este enfoque, funcionan para explicar las diferentes dinámicas sociales, incluyendo las de la vida religiosa. Por ende, el autor propone para el caso chino dos conceptos clave: el triple mercado religioso: rojo, negro y gris, y los oligopolios religiosos.

Este modelo parte de la presunción de estabilidad de la demanda religiosa y tiene como variable clave (independiente) la regulación de la religión (mecanismo de control político). En la medida en que se restrinjan las religiones, las personas aceptan lo que se ofrece (mercado rojo), mas si las rechazan, surge un mercado negro a pesar de los altos costos para los individuos; pero si además este último se suprime, emerge un complejo y volátil mercado gris, el cual será más necesario a medida que la regulación sea más restrictiva y supresora. Muchas de las religiones del mercado gris (categorizadas como cuasirreligiones o pseudorreligiones) sobreviven porque se les considera parte del patrimonio cultural y étnico. Empero, de las acciones gubernamentales resultan de las más diversas situaciones, por lo que el modelo cae en lo simplista al limitar sus posibles explicaciones en el desarrollo de un triple mercado religioso.

Con la propuesta teórico-hipotética de Yang, la verdadera vivencia sociorreligiosa pasa por el mercado gris. De acuerdo con el autor, quien se basa en 
algunos datos provenientes de fuentes secundarias (definitivamente hizo falta el trabajo empírico), hay cientos de millones de potenciales consumidores religiosos en China ${ }^{13}$, que de momento y de manera muy distinta, comparten o participan en alguna forma de creencia religiosa o espiritual. Sin embargo, a pesar de que el modelo implica una presunción de constante demanda religiosa, el autor lo encuentra demasiado simplista y reconoce que la "escasez de una economía de la religión" también da lugar a la supresión de la demanda o a muy diferentes relaciones entre ella y la oferta.

Finalmente, en el capítulo 7 , se discute que durante el gobierno del $\mathrm{PCCh}$, la religión refleja un caso de oligopolio. Para Yang, este modelo explica la coexistencia de las más diversas religiones en una dinámica de triple mercado. No hay monopolios, ni pluralismos religiosos. En China existen algunas religiones con ciertos privilegios especiales de parte del gobierno. No obstante, en Religion in China no se aclara si a las religiones sin estos privilegios se les considera ilegales o participantes del mercado negro o gris, situaciones muy distintas. Sin embargo, según Yang, el modelo de oligopolio está presente en muchos países del mundo, por lo que se puede utilizar como un marco de debate sobre los diferentes significados de la pluralidad, la pluralización y el pluralismo de las religiones. ¿Conceptos tan amplios y complejos, y todavía aplicados a la vitalidad religiosa, los puede explicar un modelo de mercado? En el caso chino, ¿un modelo de mercado será suficiente para comprender la naturaleza sincrética milenaria de la religiosidad china, donde el confucia- nismo, el daoísmo y el budismo (por citar algunas) interactúan y se influyen entre sí, hibridando hoy en un sistema de valores en un mundo globalizado?

Otra carencia de esta propuesta es la falta de trabajo en los conceptos de lo público y lo privado, clave -se considera-, en el caso chino, donde la religión permaneció socialmente arraigada en la vida cotidiana de las mayorías debido a la imposibilidad de acceso a la esfera pública. ¿Dónde cabe esto en la teoría de triple mercado y los oligopolios religiosos?

Yang considera que su modelo puede tener aplicabilidad universal. Hace constante referencia a los gobiernos comunistas en Europa central y Asia (¿y Latinoamérica?) para señalar que su modelo de triple mercado (rojo, negro y gris) podría explicar la situación de la religión en estos países; mientras, el modelo de oligopolio lo haría con la situación contemporánea. Pero, ¿cómo aseverar esto cuando ni siquiera existe el trabajo empírico sobre el caso chino? ¿Qué pensarán de ello los especialistas de países comunistas de otras latitudes y épocas?

En síntesis, Religion in China es un trabajo útil para debatir el tema de las religiones en China bajo el gobierno del PCCh. La crítica realizada ha sido con el objetivo de abrir el camino hacia el planteamiento de nuevas problemáticas. Sobre el periodo no sólo se necesitan más planteamientos teóricohipotéticos, sino que también trabajos empíricos que reflejen la realidad contemporánea de la religiosidad china. $\mathrm{Si}$ se desea colaborar en ello, en definitiva el trabajo de Yang podría funcionar como un buen punto de partida. 


\section{Notas}

1 Traducción propia, citado en: C. K. Yang, Religion in Chinese Society (Berkeley y Los Angeles: University of California Press, 1961), 5.

2 Traducción propia, en: Yang, Religion in Chinese Society, 6.

3 A éstas podríamos agregar el programa común de 1949.

4 Rodney Stark y Roger Finke, "To the Chinese Readers", en: Xinyang de faze (Acts of Faith) (Beijing: Renmin University Press, 2004), 3.

5 János Kornai, The Socialist System:The Political Economy of Communism (Princeton University Press, 1992), 228-260.

6 Émile Durkheim, The Elementary Forms of Religious Life (Nueva York y Londres: Oxford University Press, 2001), 46.

7 E. B. Tylor, Primitive Culture (Londres: Murray, 1871).

8 Clifford Geertz, "Religion as a Cultural System", en: Anthropological Approaches to the Study of Religion, ed. M. Banton (Nueva York: Praeger, 1966), 4.

9 Nótese que en este planteamiento de ninguna manera se hace referencia al confucianismo, a pesar de que el mismo autor en otro trabajo asevera el desarrollo de un cristianismo confuciano chino. Yang, Chinese Christians in America: Conversion, Assimilation, and Adhesive Identities (Pennsylvania State University Press, 1999). Y sobre la controversia de si el confucianismo funciona como religión, véase: Yong Chen, ¿Es el confucianismo una religión? La controversia sobre la religiosidad confuciana, su significado $y$ trascendencia, trad. Abraham Navarro (México D.F.: COLMEX, 2012).

10 Marcel Granet, La pensée chinoise (París: Editions Albin Michel, 1968), 586.

11 ¿Tal vez debió pensar en religiosidad china en vez de religión china? Acerca de la pluridimensión china de lo religioso, véase: John E. Wills Jr., "Maritime in China from Wang Chih to Shih Lang", en: From Ming to Ch'ing, eds. Jonathan Spence y J. E. Wills Jr. (Yale University Press, 1979), 219. Jacques Gernet, Primeras reacciones chinas al cristianismo, trad. Carlota Vallée Lazo (México D. F.: Fondo de Cultura Económica, 1989), 86. Chen, ¿Es el confucianismo una religión?, 47-48.

12 Marcel Gauchet, La condition historique. Entretien acec F.Azouvi et S.Piron (París: Stock, 2003), 99.

13 Acerca de esto, cuando relata el desarrollo ("crecimiento") del cristianismo (págs. 141-149), lo hace con tal entusiasmo, que el uso del lenguaje religioso o eclesial -por ejemplo, titula el acápite "Spiritual Awakening" ("Despertar espiritual")-, denota su militancia (se bautizó en 1992) y aniquila su propuesta teórica. Lo anterior, a pesar de que Yang considera que el trabajo científico debe estar libre de valores (pág. 29).

\section{Bibliografía}

Yang, Fenggang. Religion in China. Survival \& Revival under Communist Rule. Nueva York: Oxford University Press, 2012. 245 páginas. 